\title{
Comparison of Reverse Transcription Quantitative Real-Time PCR, Flow Cytometry, and Immunohistochemistry for Detection of Monoclonality in Lymphomas
}

\author{
Anders Ståhlberg, ${ }^{1,2}$ Pierre Åman, ${ }^{1}$ Linda Strömbom, ${ }^{1,2}$ Neven Zoric, ${ }^{2}$ Alfredo Diez, ${ }^{1}$ \\ Olle Nilsson, ${ }^{3}$ Mikael Kubista, ${ }^{2,4}$ and Börje Ridell ${ }^{1}$ \\ ${ }^{1}$ Sahlgrenska Cancer Center, Sahlgrenska Academy, University of Gothenburg, 40530 Gothenburg, Sweden \\ ${ }^{2}$ TATAA Biocenter, Odinsgatan 28, 41103 Gothenburg, Sweden \\ ${ }^{3}$ Fujirebio Diagnostics AB, Elof Lindälvs Gata 13, 40242 Gothenburg, Sweden \\ ${ }^{4}$ Institute of Biotechnology AS CR, Videnska 1083, 14220 Prague 4, Czech Republic \\ Correspondence should be addressed to Pierre Åman; pierre.aman@llcr.med.gu.se
}

Received 26 November 2013; Accepted 24 December 2013; Published 4 February 2014

Academic Editors: Y. Akiyama and T. Kozu

Copyright (C) 2014 Anders Ståhlberg et al. This is an open access article distributed under the Creative Commons Attribution License, which permits unrestricted use, distribution, and reproduction in any medium, provided the original work is properly cited.

\begin{abstract}
In healthy humans, $60-70 \%$ of the B lymphocytes produce kappa light chains, while the remaining cells produce lambda light chains. Malignant transformation and clonal expansion of B lymphocytes lead to an altered kappa : lambda expression ratio, which is an important diagnostic criteria of lymphomas. Here, we compared three methods for clonality determination of suspected B cell lymphomas. Tumor biopsies from 55 patients with B cell malignancies, 5 B-lymphoid tumor cell lines, and 20 biopsies from patients with lymphadenitis were analyzed by immunohistochemistry, flow cytometry, and reverse transcription quantitative real-time PCR. Clonality was determined by immunohistochemistry in 52/53 cases, flow cytometry in 30/39 cases, and reverse transcription quantitative real-time PCR in 33/55 cases. In conclusion, immunohistochemistry was superior to flow cytometry and reverse transcription quantitative real-time PCR for clonality identification. Flow cytometry and reverse transcription quantitative real-time PCR analysis has complementary values. In a considerable number of cases tumor cells produced both kappa and lambda light chain transcripts, but only one type of light chain peptide was produced.
\end{abstract}

\section{Introduction}

B lymphocytes produce immunoglobulins consisting of a heavy chain and either a kappa $(I G K C)$ or a lambda (IGLC) light chain. Each B lymphocyte decides early by the rearrangement of its immunoglobulin genes which light chain to produce [1]. The excluded light chain gene is not properly rearranged or remains in germ line configuration [2]. In healthy humans $60-70 \%$ of the B cells produce kappa chains and the rest produce lambda chains $[1,3]$. Normal lymphoid tissues therefore contain a mixture of $\mathrm{B}$ cells that express $I G K C$ and $I G L C$ at a ratio of about $60: 40=1.5$.

Tumors of B cell origin are monoclonal and arise from one transformed cell. The single cell origin of malignant clones results in exclusive expression of IGKC or IGLC light chains in the vast majority of all B cell malignancies although B cell tumors that produce both kappa and lambda chains have been reported [4]. The clonal expression of IGKC or $I G L C$ is thus used as an important diagnostic marker for B cell malignancies and currently determined on protein level by immunohistochemistry (IHC), flow cytometry (FC), or enzyme-linked immunosorbent assay techniques. Previously, we used reverse transcription quantitative real-time PCR (RT-qPCR) to quantify IGKC and IGLC gene transcripts in a small set of lymphomas and found that also gene expression level clonality was frequently evident [5]. In the present study we have used the same RT-qPCR method together with IHC and FC to analyze a larger cohort of 39 nonHodgkin lymphomas, 16 chronic lymphatic leukemias, and 5 $\mathrm{B}$ cell derived tumor cell lines. The non-Hodgkin lymphomas 
TABLE 1: Detailed patient information.

\begin{tabular}{|c|c|c|c|c|c|c|}
\hline Sample ID & Classification & Gender & Age & FC & IHC & RT-qPCR \\
\hline 111 & CLL & $\mathrm{F}$ & 70 & $\mathrm{ND}$ & Lambda & Lambda \\
\hline 112 & CLL & $\mathrm{F}$ & 82 & ND & Lambda & MNP \\
\hline 113 & CLL & M & 58 & Lambda & Lambda & Lambda \\
\hline 115 & CLL & $\mathrm{F}$ & 61 & Lambda & Lambda & Lambda \\
\hline 116 & CLL & $\mathrm{F}$ & 57 & Kappa & Kappa & Kappa \\
\hline 117 & CLL & $\mathrm{F}$ & 75 & Kappa & Kappa & Kappa \\
\hline 118 & CLL & $\mathrm{F}$ & 85 & Kappa & Kappa & Kappa \\
\hline 119 & CLL & $\mathrm{F}$ & 48 & $\mathrm{ND}$ & Lambda & Lambda \\
\hline 131 & CLL & M & 72 & ND & Lambda & Lambda \\
\hline 132 & CLL & $\mathrm{F}$ & 59 & $\mathrm{ND}$ & Lambda & Lambda \\
\hline 145 & CLL & $\mathrm{F}$ & 76 & Kappa & Kappa & MNP \\
\hline 146 & CLL & M & 46 & Lambda & Lambda & Lambda \\
\hline 147 & CLL & $\mathrm{F}$ & 74 & Kappa & Kappa & Kappa \\
\hline 149 & CLL & $\mathrm{F}$ & 76 & Kappa & Kappa & MNP \\
\hline 189 & CLL & $\mathrm{F}$ & 65 & Kappa & Kappa & MNP \\
\hline 191 & CLL & M & 60 & Lambda & Lambda & Lambda \\
\hline 120 & DLBL & M & 80 & ND & Kappa & MNP \\
\hline 121 & DLBL & M & 81 & ND & Kappa & Kappa \\
\hline 123 & DLBL & $\mathrm{M}$ & 64 & Kappa & Kappa & Kappa \\
\hline 124 & DLBL & $\mathrm{F}$ & 77 & Kappa & Kappa & Kappa \\
\hline 125 & DLBL & $\mathrm{M}$ & 57 & ND & MNP & Lambda \\
\hline 126 & DLBL & $\mathrm{M}$ & 70 & Lambda & Lambda & Lambda \\
\hline 127 & DLBL & M & 70 & Kappa & Kappa & Kappa \\
\hline 129 & DLBL & $\mathrm{M}$ & 58 & ND & Kappa & MNP \\
\hline 133 & DLBL & $\mathrm{M}$ & 72 & MNP & Lambda & MNP \\
\hline 135 & DLBL & $\mathrm{F}$ & 75 & MNP & Kappa & Kappa \\
\hline 136 & DLBL & $\mathrm{F}$ & 78 & $\mathrm{ND}$ & Kappa & MNP \\
\hline 137 & DLBL & $\mathrm{M}$ & 70 & Kappa & Kappa & Kappa \\
\hline 138 & DLBL & $\mathrm{M}$ & 72 & ND & Kappa & MNP \\
\hline 139 & DLBL & $\mathrm{M}$ & 33 & Kappa & Kappa & Kappa \\
\hline 140 & DLBL & $\mathrm{F}$ & 78 & Kappa & Kappa & kappa \\
\hline 153 & DLBL & $\mathrm{M}$ & 19 & ND & Карpa & Kappa \\
\hline 156 & DLBL & $\mathrm{M}$ & 58 & Kappa & Kappa & Kappa \\
\hline 182 & DLBL & $\mathrm{F}$ & 75 & MNP & Карра & MNP \\
\hline 184 & DLBL & $\mathrm{M}$ & 55 & Kappa & Kappa & Kappa \\
\hline 186 & DLBL & $\mathrm{F}$ & 66 & Kappa & Карра & Kappa \\
\hline 157 & FL & $\mathrm{F}$ & 54 & Kappa & Kappa & MNP \\
\hline 158 & FL & $\mathrm{F}$ & 51 & ND & Kappa & MNP \\
\hline 159 & $\mathrm{FL}$ & $\mathrm{M}$ & 77 & ND & Kappa & MNP \\
\hline 160 & $\mathrm{FL}$ & $\mathrm{F}$ & 60 & ND & Lambda & MNP \\
\hline 161 & $\mathrm{FL}$ & $\mathrm{M}$ & 70 & Lambda & Lambda & MNP \\
\hline 162 & FL & $\mathrm{M}$ & 69 & Kappa & Kappa & Kappa \\
\hline 163 & FL & $\mathrm{M}$ & 52 & Kappa & Kappa & Kappa \\
\hline 164 & FL & $\mathrm{M}$ & 53 & ND & Kappa & Kappa \\
\hline 165 & FL & $\mathrm{F}$ & 59 & Kappa & Kappa & MNP \\
\hline 166 & $\mathrm{FL}$ & $\mathrm{M}$ & 61 & MNP & Карра & MNP \\
\hline 167 & FL & $\mathrm{F}$ & 30 & MNP & Lambda & MNP \\
\hline 168 & $\mathrm{FL}$ & $\mathrm{M}$ & 51 & MNP & Карра & Kappa \\
\hline 208 & $\mathrm{FL}$ & $\mathrm{F}$ & 83 & MNP & $\mathrm{ND}$ & MNP \\
\hline
\end{tabular}


TABle 1: Continued.

\begin{tabular}{|c|c|c|c|c|c|c|}
\hline Sample ID & Classification & Gender & Age & FC & IHC & RT-qPCR \\
\hline 209 & FL & $\mathrm{F}$ & 55 & Lambda & Lambda & Lambda \\
\hline 210 & FL & $\mathrm{F}$ & 46 & MNP & Kappa & MNP \\
\hline 211 & FL & M & 64 & Lambda & ND & MNP \\
\hline 204 & MCL & M & 61 & Lambda & Lambda & Lambda \\
\hline 206 & MCL & $\mathrm{F}$ & 78 & Kappa & Kappa & Kappa \\
\hline 207 & MCL & $\mathrm{F}$ & 70 & Kappa & Kappa & MNP \\
\hline 101 & LA & $\mathrm{F}$ & 62 & ND & MNP & Control \\
\hline 102 & LA & M & 25 & ND & MNP & Control \\
\hline 103 & LA & M & 25 & ND & MNP & Control \\
\hline 104 & LA & M & 16 & ND & MNP & Control \\
\hline 105 & LA & $\mathrm{F}$ & 58 & ND & MNP & Control \\
\hline 106 & LA & M & 59 & ND & MNP & Control \\
\hline 107 & LA & M & 41 & ND & MNP & Control \\
\hline 108 & LA & M & 7 & ND & MNP & Control \\
\hline 109 & LA & $\mathrm{F}$ & 33 & ND & MNP & Control \\
\hline 110 & LA & $\mathrm{F}$ & 28 & ND & MNP & Control \\
\hline 192 & LA & $\mathrm{F}$ & 1 & MNP & MNP & Control \\
\hline 193 & LA & $\mathrm{F}$ & 40 & MNP & MNP & Control \\
\hline 194 & LA & M & 28 & MNP & MNP & Control \\
\hline 195 & LA & M & 20 & MNP & MNP & Control \\
\hline 196 & LA & $\mathrm{M}$ & 13 & MNP & MNP & Control \\
\hline 197 & LA & M & 30 & MNP & MNP & Control \\
\hline 198 & LA & $\mathrm{F}$ & 10 & MNP & MNP & Control \\
\hline 199 & LA & $\mathrm{F}$ & 58 & MNP & MNP & Control \\
\hline 200 & LA & $\mathrm{M}$ & 49 & MNP & MNP & Control \\
\hline 201 & LA & $\mathrm{F}$ & 57 & MNP & MNP & Control \\
\hline
\end{tabular}

CLL: chronic lymphocytic leukemia; DLBL: diffuse large B cell lymphoma; FL: follicular lymphoma; LA: lymphadenitis; F: female; M: male; MNP: monoclonality not proven; FC: flow cytometry; IHC: immunohistochemistry.

TABLE 2: Monoclonal populations detected in lymphoma and lymphadenitis biopsies ${ }^{\mathrm{a}}$.

\begin{tabular}{lccc}
\hline & RT-qPCR & FC & IHC \\
\hline CLL & $12 / 16$ & $11 / 11$ & $16 / 16$ \\
DLBL & $14 / 20$ & $10 / 13$ & $19 / 20$ \\
FL & $5 / 16$ & $6 / 12$ & $14 / 14$ \\
MCL & $2 / 3$ & $3 / 3$ & $3 / 3$ \\
CLL/lymphoma total & $33 / 55$ & $30 / 39$ & $52 / 53$ \\
LA & $0 / 20$ & $0 / 10$ & $0 / 20$ \\
\hline
\end{tabular}

${ }^{a}$ Number of samples with clonality proven/total number of samples is shown. CLL: chronic lymphocytic leukemia; DLBL: diffuse large B cell lymphoma; FL: follicular lymphoma; MCL: mantle cell lymphoma; LA: lymphadenitis (polyclonal control).

consisted of 20 diffuse large B cell lymphomas, 16 follicular lymphomas, and 3 mantle cell lymphomas.

\section{Material and Methods}

2.1. Biopsies, Flow Cytometry, and Immunohistochemistry. The samples were transported from the operation theatre in ice-water-chilled boxes, handled in the laboratory within
$30 \mathrm{~min}$, and stored at $-140^{\circ} \mathrm{C}$. Parts of the tissues were fixed in formalin and embedded in paraffin according to the routine protocols of the pathology laboratory. Diagnosis was reached by a combination of microscopic histological evaluation, IHC of several markers, including the $\kappa$ and $\lambda$ chains, and in some cases by FC. Series of $5 \mu \mathrm{m}$ tissue sections were cut from each biopsy, deparaffinized, rehydrated, and stained with the following antibodies: rabbit anti-human kappa light chains and rabbit anti-human lambda chains (A0191 and A0194, DAKO). The antibodies were used at a dilution of 1:400 and bound antibodies were visualized using the second labeled antibody streptavidin biotin peroxidase system (DAKO). Stained sections were examined with a light microscope. For FC, a routine protocol for preparation of lymphoid cells from lymphoma tissue was used. Direct labeled antibodies specific for immunoglobulin kappa and lambda chains (A0191 and A0194, DAKO) were used for staining of recovered cells. First a gate for lymphocytes was set using forward and side scatter, followed by gates for kappa and lambda staining cells. We used a kappa:lambda ratio less than 0.4 or greater than 5 to prove FC monoclonality [6]. The samples were classified according to the Revised European-American Lymphoma and World Health Organization classification system. 
2.2. RNA Extraction and RT-qPCR. RNA was extracted by use of the Fast Prep System (FastRNA Green; Qbiogene). We mixed $10 \mu \mathrm{g}$ of total RNA with $2 \mu \mathrm{g}$ of poly (dT) oligomers (Pharmacia) and incubated the mixture at $65^{\circ} \mathrm{C}$ for $5 \mathrm{~min}$. First-strand cDNA synthesis was performed by adding $0.05 \mathrm{~mol} / \mathrm{L}$ Tris- $\mathrm{HCl}$ ( $\mathrm{pH} 8.3$ ), $0.075 \mathrm{~mol} / \mathrm{L} \mathrm{KCl}, 3 \mathrm{mmol} / \mathrm{L}$ $\mathrm{MgCl}_{2}, 0.01 \mathrm{~mol} / \mathrm{L}$ dithiothreitol, $10 \mathrm{U} / \mathrm{mL}$ Moloney murine leukemia virus reverse transcriptase (Life Technologies), 0.05 units $/ \mathrm{mL}$ RNA guard (Life Technologies), and $10 \mathrm{mmol} / \mathrm{L}$ of each deoxyribonucleotide (Life Technologies) to a final volume of $20 \mu \mathrm{L}$ and incubating the samples at $37^{\circ} \mathrm{C}$ for $1 \mathrm{~h}$. The reaction was terminated by incubation at $65^{\circ} \mathrm{C}$ for $5 \mathrm{~min}$, and samples were stored at $-80^{\circ} \mathrm{C}$. Real-time PCR measurements were performed on a Rotorgene 3000 (Corbett Research). Each PCR reaction contained $10 \mathrm{mmol} / \mathrm{L}$ Tris- $\mathrm{HCl}$ pH 8.3, $50 \mathrm{mmol} / \mathrm{L} \mathrm{KCl,} 4 \mathrm{mM} \mathrm{MgCl}_{2}, 400 \mu \mathrm{mol} / \mathrm{L}$ each dNTP, $300 \mathrm{nmol} / \mathrm{L}$ each primer, $0.04 \mathrm{U} / \mu \mathrm{L}$ Jumpstart Taq (Sigma), and 0.25x SYBR Green (Molecular Probes) in a $20 \mu \mathrm{L}$ reaction volume. The temperature profile was $95^{\circ} \mathrm{C}$ for $3 \mathrm{~min}$ followed by 40 cycles of amplification $\left(95^{\circ} \mathrm{C}\right.$ for $20 \mathrm{sec}$, $60^{\circ} \mathrm{C}$ for $20 \mathrm{sec}$, and $72^{\circ} \mathrm{C}$ for $20 \mathrm{sec}$ ). Primer sequences and detailed assay performance for IGKC and IGLC are reported elsewhere [5]. Formation of correctly sized PCR products was confirmed by agarose gel electrophoresis for all assays and melting curve analysis for all samples. RT-qPCR and statistical analysis of the data were performed as previously described [5]. A 95\% confidence region for the IGKC:IGLC ratio using the negative lymphadenitis was used to prove RT-qPCR monoclonality.

2.3. RT-PCR Cloning and Sequencing. PCR products were obtained as for QPCR analysis and fractionated by agarose electrophoresis. Fragments were excised from the gels and used as templates for DNA sequencing as previously described [7].

\section{Results and Discussion}

The samples were analyzed by IHC, FC, and RT-qPCR for expression of IGKC and IGLC light chains (Tables 1 and 2). IHC indicated an exclusive or heavily dominant expression of IGKC or IGLC chains indicative of a monoclonal origin in all but one analyzed samples (98\%). RT-qPCR analysis indicated a monoclonal dominance in 33 of 55 (60\%) analyzed samples, while FC scored monoclonal dominance in 30 of 39 (77\%) analyzed samples. Thus the IHC method was superior to FC and RT-qPCR in detecting monoclonality. The divergent results may in part be explained by the fact that biopsies, besides the tumor cells, often contain considerable numbers of normal lymphocytes that could contribute to the RNA samples analyzed by RT-qPCR and the cell population studied by flow cytometry. IHC analysis, on the other hand, allows for selective analysis of representative parts of the tumor tissue thus avoiding contribution of normal B lymphocytes. Furthermore, it is also known that $60-70 \%$ of non-Hodgkin lymphomas lack surface expression of IGLK and IGLC [8].

FC was more efficient than RT-qPCR in identifying clonal populations. However, there was an overall good correlation in expression levels of IGKC and IGLC between FC and

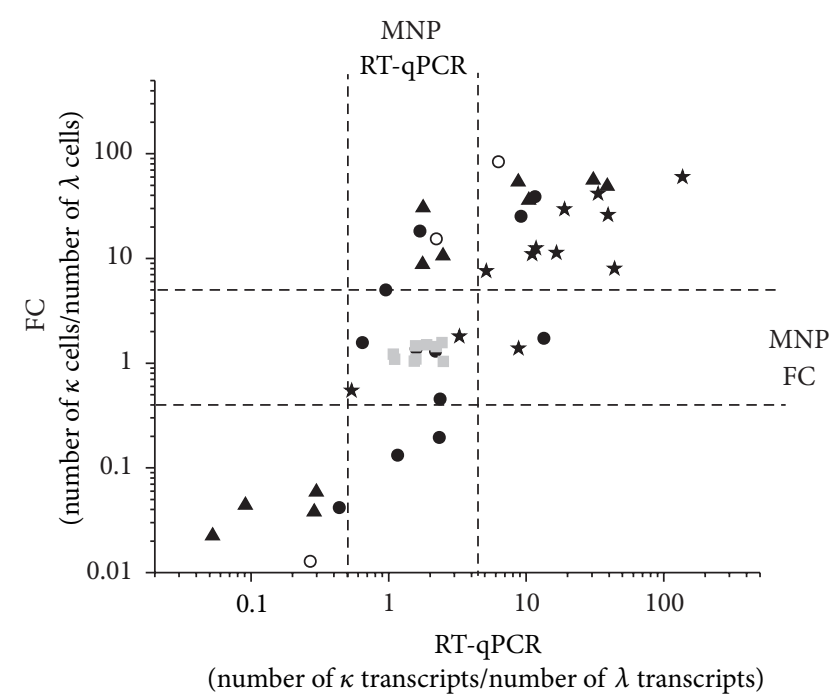

FIGURE 1: Comparison of IGKC: IGLC ratio between FC and RTqPCR. The Pearson correlation coefficient is $0.65(P<0.01)$. The FC ratio refers to cell number, while the RT-qPCR ratio refers to transcript number. The areas where no monoclonality (MNP) could be proven are shown as dashed lines. Grey square, lymphadenitis; stars, diffuse large B cell lymphoma; triangles, chronic lymphocytic leukemia; dot, follicular lymphoma; circles, mantle cell lymphoma; $\kappa$, IGKC; $\lambda$, IGLC.

RT-qPCR data despite the fact that FC data reflects cell number and RT-qPCR data reflects transcript numbers (Figure 1). In two cases (samples 135 and 168, Table 1), RT-qPCR detected clonal populations where FC failed. RT-qPCR may therefore serve as a valuable complement to IHC and FC in detection of monoclonal B cell populations. Moreover, RT-qPCR analysis can also be employed on minute fine needle aspirate samples that are not sufficient for flow cytometry or IHC and the same sample may also be analyzed simultaneously for expression of more marker genes.

Several of the IGKC and IGLC cotranscribing tumors appeared by IHC and FC to consist of homogenous tumor cell populations with no or few normal lymphocytes suggesting that some malignant $\mathrm{B}$ cell clones were dual producers of light chain mRNA (Figure 2). Dual production of IGLC chain mRNAs and proteins has been reported for various types of malignant B cell clones and normal B lymphocytes [4, 9]. These reports and our data prompted us to analyze five monoclonal B cell derived tumor cell lines (Table 3 ). These cell lines produce only one light chain species as analyzed by immunofluorescence, but four of them contained both $I G K C$ and IGLC transcripts. To further confirm this result we isolated PCR products from two of the cell lines and sequence analysis showed that IGKC and IGLC transcripts were indeed produced simultaneously in these cell lines. Thus we conclude that human monoclonal B-lymphoid populations frequently simultaneously produce IGKC and IGLC transcripts.

We searched for possible correlations between dual light chain producers and tumor type. Dual producers were most common in the follicular lymphoma group in which 11/16 
TABLE 3: RT-qPCR data for 5 B-lymphoid tumor cell lines.

\begin{tabular}{|c|c|c|c|c|c|c|}
\hline Cellinje & Kappa Cq & Lambda Cq & Kappa noRT Cq & Lambda noRT Cq & mRNA expression & IHC \\
\hline U698 & 10.3 & 13.8 & 27 & 23.5 & Kappa > Lambda & Kappa \\
\hline DG75 & 10.4 & 15.9 & 25.2 & 24.2 & Kappa > Lambda & Kappa \\
\hline MC116 & 34.8 & 10.4 & Not detected & 23.5 & Lambda only & Lambda \\
\hline RPMI8226 & 12.2 & 14.4 & 25.1 & 22.2 & Kappa > Lambda & Lambda \\
\hline CCRF-SB & 12.3 & 11.2 & 26.7 & 24.4 & Lambda $</ \approx$ Kappa & Kappa \\
\hline Neg. control & $>33$ & $\sim 30$ & & & & \\
\hline
\end{tabular}

Cq: cycle of quantification (log transcript numbers); noRT: samples without reverse transcriptase; IHC: immunohistochemistry.

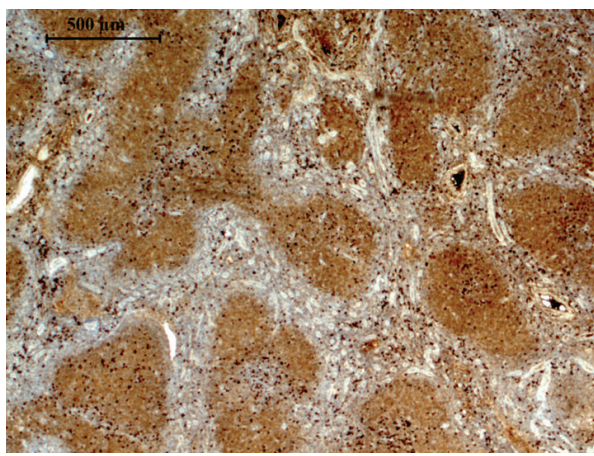

(a)

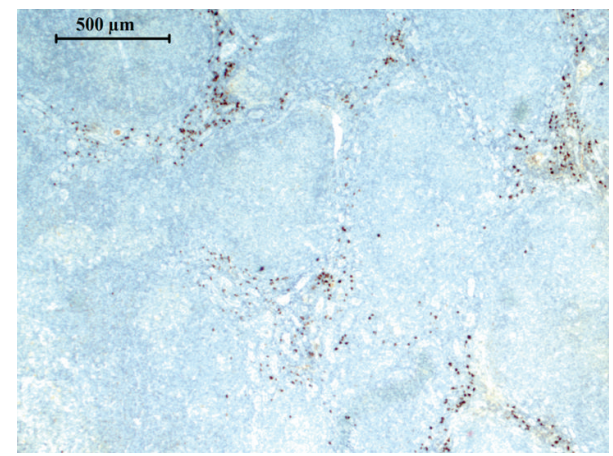

(b)

FIgURE 2: Immunohistochemistry of sample 165. The follicular lymphoma sample 165 was stained for (a) IGKC and (b) IGLC. Using RT-qPCR no clonality could be proven for this IGKC IHC positive sample.

tumors failed to score for monoclonality based on RTqPCR analysis. This could possibly be explained by larger abundance of normal cells in follicular lymphomas since FC showed highest failure rate for these samples, and may also depend on a higher frequency of dual producers.

Eleven of twelve cases where monoclonality was not detected by RT-qPCR produced IGKC protein as judged by IHC. This is more than expected from the normal ratio of IGKC and IGLC producers among normal B lymphocytes and lymphoma populations. In the present cohort of IHC investigated lymphomas, $30 \%$ were lambda producers. Thus, it is possible that dual mRNA producers arise more often among kappa protein producing cells. This is surprising since kappa chains are considered to be rearranged first and IGLC rearrangement is pursued only if $I G K C$ rearrangement fails to produce a functional IGKC protein [10]. The activation of IGLC transcription is most likely a result of rearrangement that occurs after IGKC protein is produced and may therefore indicate a failure to inactivate the rearrangement mechanism. Failure to regulate a potentially risky DNA rearrangement process may also contribute to the frequent multiple genetic rearrangements in lymphomas. Age and gender were not correlated to the determined clonality (data not shown).

\section{Conclusions}

We conclude that IHC, FC, and RT-qPCR analysis of human $\mathrm{B}$-lymphoid tumors gives partially divergent results. This may in part be explained by contribution of normal B lymphocytes into the tumor tissue. Our results also suggest that dual transcription of IGKC and IGLC loci is common in these tumors. This has to be taken in consideration when RT-qPCR analysis of IGKC and IGLC is used for diagnostic purpose. RT-qPCR remains an interesting complement for diagnostic purpose when only small samples, such as from fine needle cytology, are available.

\section{Conflict of Interests}

The IGKC-IGLC RT-qPCR test is patent granted (WO02099135).

\section{Acknowledgments}

This work was supported by Swedish Society for Medical Research, Swedish Cancer Foundation, Swedish Children Cancer Foundation, Swedish Research Council, LUA-ALF grants, BioCARE National Strategic Research Program at University of Gothenburg, Ministry of Health Grant-IGA-NS (NS 9976-3), and Grant Agency of the Czech Republic (IAA500970904).

\section{References}

[1] R. Levy, R. Warnke, R. F. Dorfman, and J. Haimovich, "The monoclonality of human B cell lymphomas," Journal of Experimental Medicine, vol. 145, no. 4, pp. 1014-1028, 1977.

[2] H.-E. Liang, L.-Y. Hsu, D. Cado, and M. S. Schlissel, "Variegated transcriptional activation of the immunoglobulin $\kappa$ locus in 
pre-B cells contributes to the allelic exclusion of light-chain expression," Cell, vol. 118, no. 1, pp. 19-29, 2004.

[3] S. Barandun, A. Morell, F. Skvaril, and A. Oberdorfer, "Deficiency of kappa or $\lambda$ type immunoglobulins," Blood, vol. 47, no. 1, pp. 79-89, 1976.

[4] D. Xu, "Dual surface immunoglobulin light-chain expression in B-cell lymphoproliferative disorders," Archives of Pathology and Laboratory Medicine, vol. 130, no. 6, pp. 853-856, 2006.

[5] A. Ståhlberg, P. Åman, B. Ridell, P. Mostad, and M. Kubista, "Quantitative real-time PCR method for detection of B-lymphocyte monoclonality by comparison of $\kappa$ and $\lambda$ immunoglobulin light chain expression," Clinical Chemistry, vol. 49, no. 1, pp. 51-59, 2003.

[6] A. Chizuka, Y. Kanda, Y. Nannya et al., "The diagnostic value of kappa/lambda ratios determined by flow cytometric analysis of biopsy specimens in B-cell lymphoma," Clinical and Laboratory Haematology, vol. 24, no. 1, pp. 33-36, 2002.

[7] M. Göransson, E. Elias, A. Ståhlberg, A. Olofsson, C. Andersson, and P. Åman, "Myxoid liposarcoma FUS-DDIT3 fusion oncogene induces $\mathrm{C} / \mathrm{EBP} \beta$-mediated interleukin 6 expression," International Journal of Cancer, vol. 115, no. 4, pp. 556-560, 2005.

[8] L. J. Picker, L. M. Weiss, and L. J. Medeiros, "Immunophenotypic criteria for the diagnosis of non-Hodgkin's lymphoma," The American Journal of Pathology, vol. 128, no. 1, pp. 181-201, 1987.

[9] C. Giachino, E. Padovan, and A. Lanzavecchia, " $k+\lambda+$ Dual receptor B cells are present in the human peripheral repertoire," Journal of Experimental Medicine, vol. 181, no. 3, pp. 1245-1250, 1995.

[10] F. W. Alt, V. Enea, A. L. M. Bothwell, and D. Baltimore, "Activity of multiple light chain genes in murine myeloma cells producing a single, functional light chain," Cell, vol. 21, no. 1, pp. 1-12, 1980. 


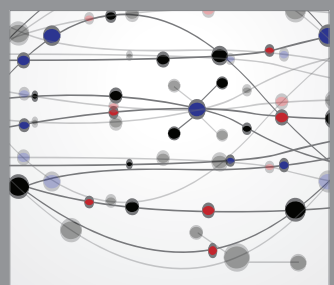

The Scientific World Journal
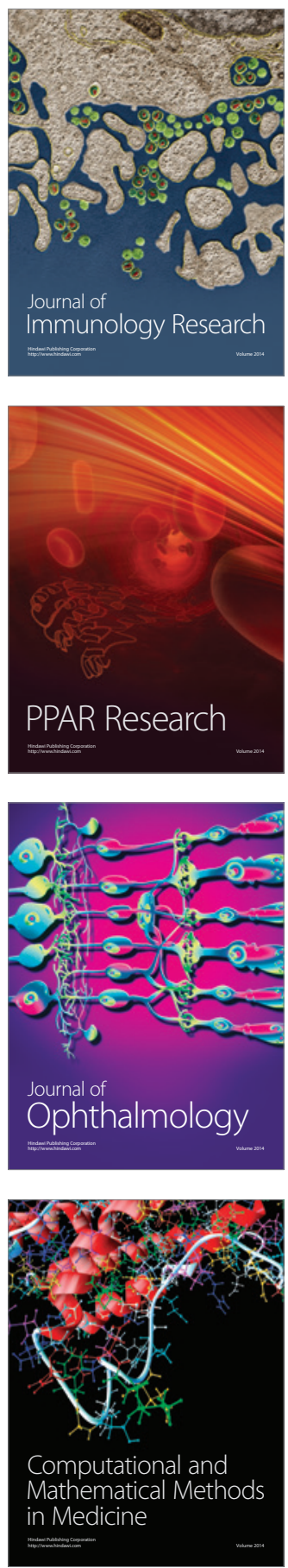

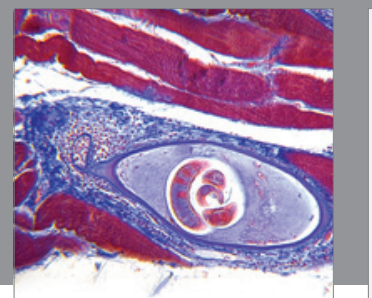

Gastroenterology

Research and Practice
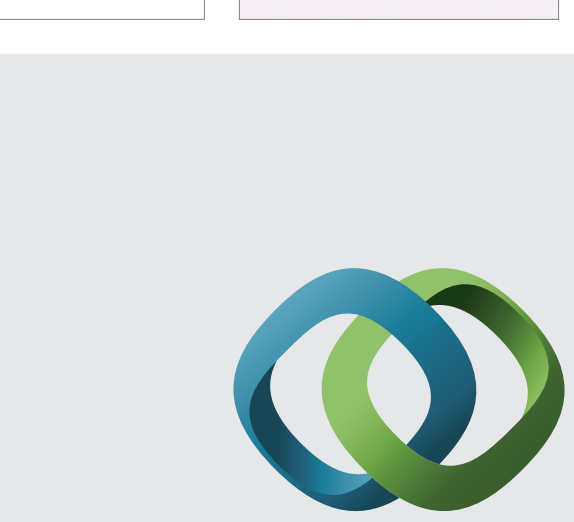

\section{Hindawi}

Submit your manuscripts at

http://www.hindawi.com
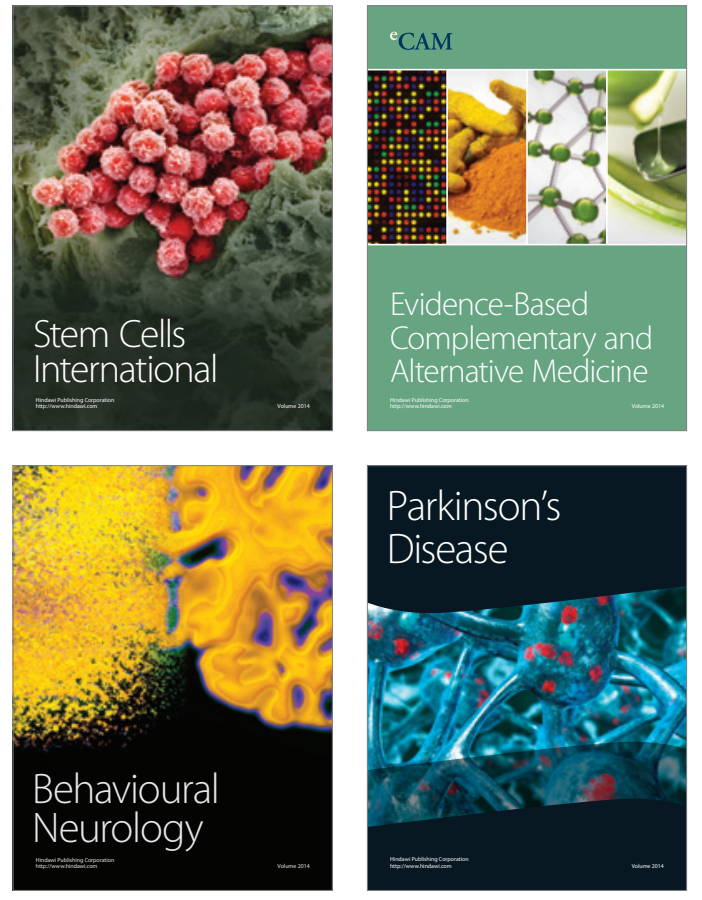
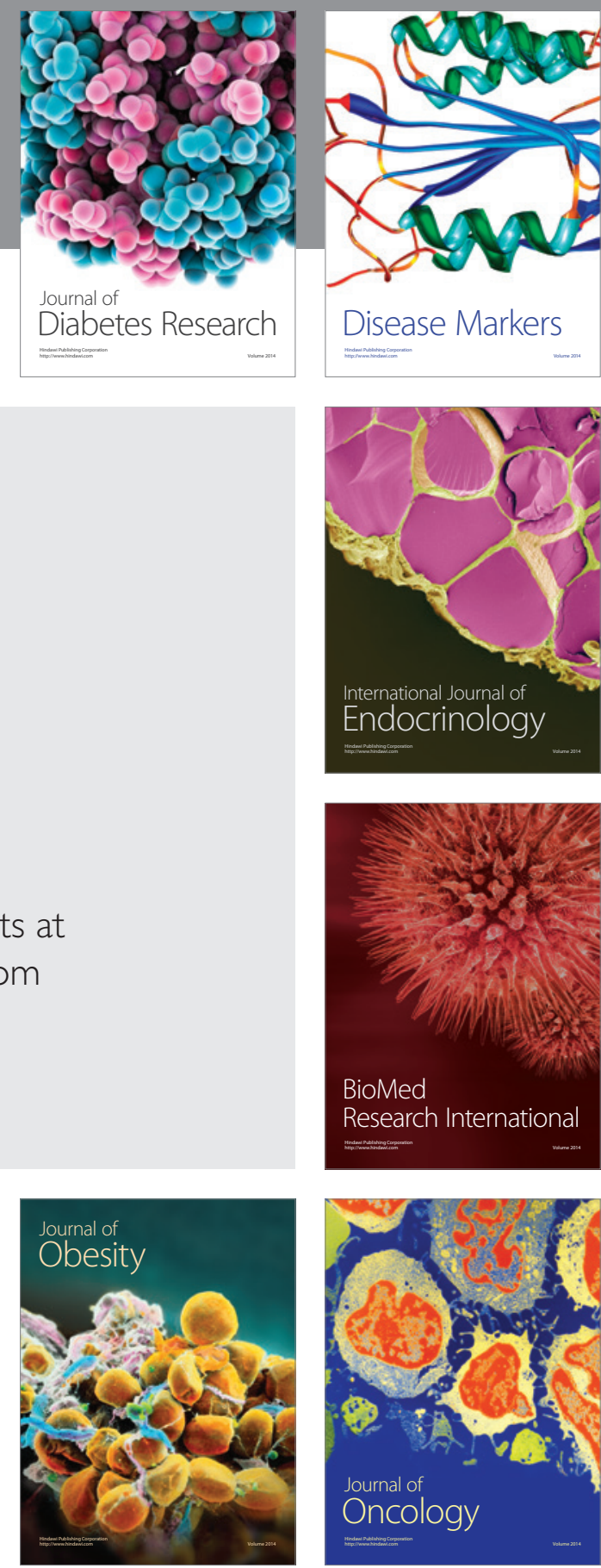

Disease Markers
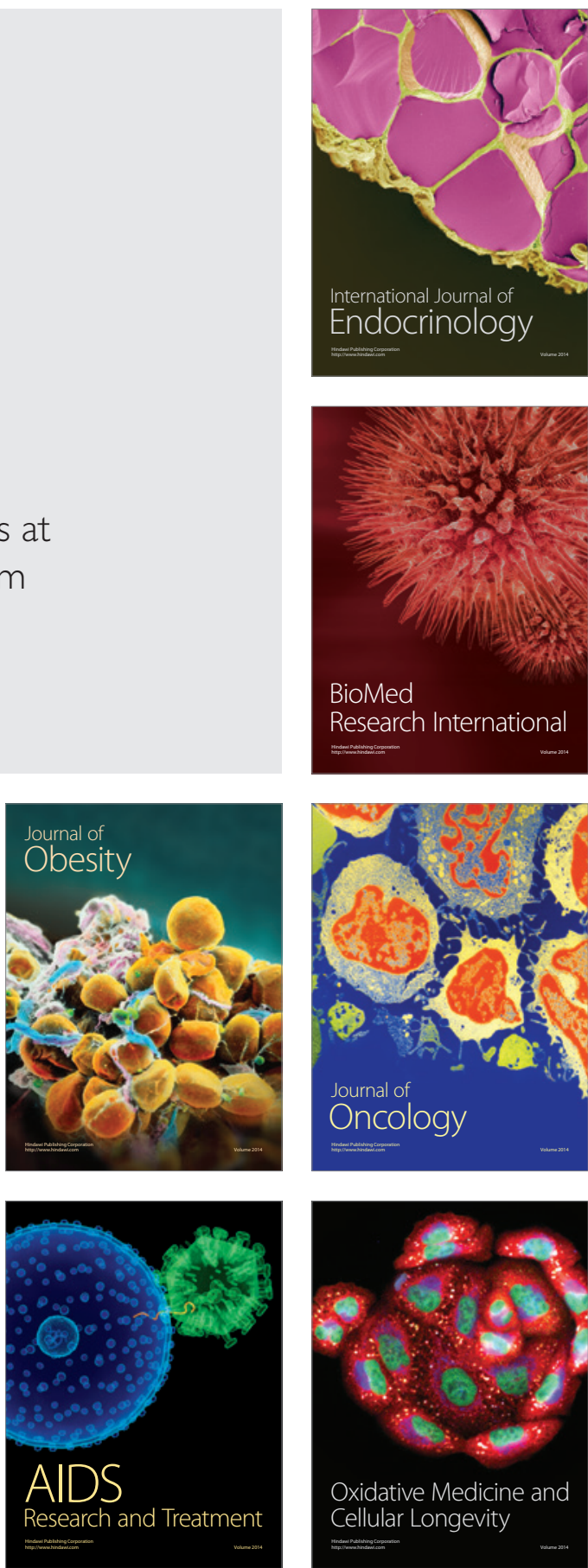